\title{
REESCRAVIZAÇÃO DE CRIANÇAS INGÊNUAS EM FEIRA DE SANTANA, 1871 - 1885
}

\author{
Bruna Santana da Silva ${ }^{1}$; Ione Celeste de Jesus Sousa ${ }^{2}$ \\ 1. Bolsista PIBIC/CNPq, Graduando em Licenciatura em História, Universidade Estadual de Feira de Santana, e- \\ mail: bssilva.fsa@gmail.com \\ 2. Orientador, Departamento de Ciências Humanas e Filosofia, Universidade Estadual de Feira de Santana, e-mail: \\ ionecjs@gmail.com
}

PALAVRAS-CHAVE: Ingênuos; Escravidão; Feira de Santana

\section{INTRODUÇÃO}

O presente trabalho apresenta pesquisa sobre táticas de reescravização de crianças ingênuas ao trabalho servil, em Feira de Santana, entre a promulgação da Lei 2040 de 28 de setembro de 1871, conhecida como Rio Branco (1871) ou do Ventre Livre - e o ano de 1885, quando registros sobre estes sujeitos começaram a rarear. Fazem parte de pesquisa de Bolsa de Iniciação Cientifica que objetiva investigar escrituras de compras e vendas de mães escravas com os seus filhos ingênuos; cartas de liberdade de escravas, em busca de indícios sobre o uso da mão de obra dessas crianças livres para o trabalho em práticas próximas ao cativeiro.

Nesta comunicação as fontes utilizadas são apenas dois processos de compra e venda de escravas da região do município de Feira de Santana, que trazem a especificidade de registrarem seus filhos ingênuos como parte da transação. São documentos disponíveis no Arquivo Público Municipal de Feira de Santana. Utilizo a bibliografia sobre o tema, com autores como Gicelle Alaniz, Maria Aparecida Papali, Milena Perussato. Para a Bahia, Ione Sousa (2006, 2008, 2015) e Giovanna Gusmão (2016).

\section{MATERIAL E MÉTODOS OU METODOLOGIA (ou equivalente)}

Para efetuar a investigação sobre a praticas de reescravização de ingênuos nascidos de escravas mães proponho a metodologia que Walter Fraga (2006) usou denominada de "ligação nominativa de fontes", já difundido anteriormente por Robert Slenes (1999), nos seus estudos sobre a família escrava no Brasil, cujo origem é a proposta metodológica de Carlo GINZBURG (1991) em o Nome e o Como, que consiste em estudar através do campo da Micro-História, os aspectos que são relevantes para entender os problemas sociais ou culturais que o historiador se dispõe em pesquisar, dentro campos e recortes menores, procurando enxergar através desses pequenos problemas, questões que podem motivar a novas produções e abordagens 
historiográficas. Os documentos da pesquisa estão no Acervo do Arquivo Público Municipal de Feira de Santana. Composto por diversos livros de escrituração, atas e de livros de notas que permitirão analisar a pratica de venda de escravas mães com seus filhos ingênuos.

\section{RESULTADOS E/OU DISCUSSÃO (ou Análise e discussão dos resultados)}

Seguindo os passos destes/as historiadores/as, busquei investigar como no município de Feira de Sant'anna localizada no sertão baiano, registros que apresentassem a manutenção de práticas escravistas referentes a criança ingênua, destacando práticas de resecravização, pouca investigadas neste campo ainda também O ingênuo, apesar de livre desde o ventre, ou no uso do título de Perussato "Como se de ventre livre nascesse", nascia e crescia na lógica do trabalho escravo, sofrendo tentativas de direta reescravização. Documentação do período evidenciam os registros de compra e venda de mulheres escravizadas que muitas vezes foram vendidas com o serviço de seus filhos ingênuos também anunciados, configurando assim um processo de reescravização, contrariando o primeiro artigo da Lei 2040.Contudo, considero que também existem nestas fontes a indicação da função do ingênuo como mão de obra imediata ou futura para o senhor que acabara de comprar sua mãe, em tentativas de reescravização.

Abaixo está listado o levantamento elaborado com os livros registrados nos aposentos do Arquivo Público Municipal de Feira de Santana, no qual, todos estes apresentam em seu conteúdo os mais diversos registros da compra e venda dessas mães escravas em que seus filhos, ingênuos, livres desde o nascimento, são associados a condição de servidão juntamente com elas.

- Livro de escrituras, $\mathrm{n}^{\circ} 359$, ano 1865-1876

- Livro ata, $\mathrm{n}^{\circ} 360$, ano $1870-1870$

- Livro de escrituras, $n^{\circ} 361$, ano 1870-1870

- Livro de escrituras, n³62, ano 1872-1879

- Livro de escrituras, n³63, ano 1872-1872

- Livro de escrituras, $n^{\circ} 364$, ano 1872-1872

- Livro de escrituras, $\mathrm{n}^{\mathrm{o}} 365$, ano 1873-1873, fl. 15f-16f

- Livro de escrituras, $\mathrm{n}^{\mathrm{o}} 365$, ano 1873-1873, fl. 21f-23v 
- Livro de escrituras, $\mathrm{n}^{\mathrm{o}}$ 365, ano 1873-1873, fl. 31f-32f

- Livro de escrituras, $\mathrm{n}^{\mathrm{o}} 365$, ano 1873-1873, fl. 32f-33f

- Livro de escrituras, $\mathrm{n}^{\mathrm{o}} 365$, ano 1873-1873, fl. 61v-62v

- Livro de escrituras, $\mathrm{n}^{\circ}$ 365, ano 1873-1873, fl. 74f-75v

- Livro de escrituras, $\mathrm{n}^{\mathrm{o}} 366$, ano 1876-1876, fl. 17v-18f

- Livro de escrituras, $\mathrm{n}^{\mathrm{o}} 366$, ano 1876-1876, fl. 2v-3v

- Livro de escrituras, $\mathrm{n}^{\mathrm{o}} 366$, ano 1876-1876, fl. 47f-47v

- Livro de escrituras, $\mathrm{n}^{\mathrm{o}} 365$, ano 1873-1873, fl. 52v-54f

- Livro de escrituras, $n^{\circ} 366$, ano 1876-1876, fl. 53v-54f

- Livro de escrituras, $n^{\circ}$ 366, ano 1876-1876, fl. 54f-56f

- Livro de escrituras, $\mathrm{n}^{\circ}$ 366, ano 1876-1876, fl. 90v-91f

- Livro de escrituras, $\mathrm{n}^{\circ} 366$, ano 1876-1876, fl. 95v-96f

- Livro de escrituras, $\mathrm{n}^{\mathrm{o}} 367$, ano 1877-1880, fl. 15v-16f

- Livro de escrituras, $\mathrm{n}^{\circ} 369$, ano 1880-1887, fl. 7v-8v

- Livro de escrituras, $\mathrm{n}^{\circ} 369$, ano 1880-1887, fl. 25v-26v

- Livro de escrituras, $\mathrm{n}^{\circ} 369$, ano 1880-1887, fl. 26v-27v

- Livro de escrituras, $n^{\circ} 369$, ano 1880-1887, fl. 32v-34f

- Livro de escrituras, $\mathrm{n}^{\circ}$ 369, ano 1880-1887, fl.110f-111v

- Livro de escrituras, $\mathrm{n}^{\circ} 369$, ano 1880-1887, fl.129v-130f

- Livro de escrituras, $\mathrm{n}^{\circ} 369$, ano 1880-1887, fl. 136v-137f

- Livro de escrituras, $\mathrm{n}^{\circ} 369$, ano 1880-1887, fl. 137v-138f

- Livro de escrituras, no 369 , ano 1880-1887, fl. 165f-165v

- Livro: 5a, ano 1876, fls 88-88v

- Livro fragmentos, ano 1877, fl. 26

- Livro fragmentos, ano 1877, fl. 28

- Livro fragmentos, ano 1877, fl. 30

- Livro fragmentos, ano 1878 , fl. $54 \mathrm{f}$

- Livro fragmentos, ano 1878, fl. $56 \mathrm{f}$

- Livro fragmentos, ano 1878, fl. $73 \mathrm{f}$

- Livro fragmentos, ano 1878 , fl. 85v

- Livro fragmentos, ano 1878 , fl. $95 \mathrm{f}$

- Livro 10, ano 1879, fl. 1

- Livro 10, ano 1879 fl. 197 
- Livro 1888, ano 1881, fl. 33v-34

- Livro 1888 , ano 1884 , fl. 249v

- Livro 1888, ano 1883, fl. 251

- Livro 1888, ano 1884, fl. 240v-241

\section{CONSIDERAÇÕES FINAIS (ou Conclusão)}

Pesquisar e tentar dar voz para aqueles se foram constantemente silenciados na historiografia é desafiante. Investigar os efeitos da Lei do Ventre quanto à questão da vida das crianças ingênuas no uso do seu trabalho permite desvendar que muitas ficaram à mercê dos senhores de suas próprias mães em situações próximas do cativeiro. Apesar de prescritas na Lei 2040 não se aplicou as medidas a fim de efetuar a educação do "filho livre da mulher escrava", daqueles que "livres como se assim nascessem" fora do cativeiro. Os incisos da lei 2040 permitiram a continuidade das gerações futuras na manutenção da prestação do trabalho escravizado.

Apesar da conclusão da bolsa de iniciação Científica, o levantamento e análise das fontes prosseguirão para além do material já manuseado; buscando novos materiais dentro dos aposentos do Arquivo Público Municipal de Feira de Santana e investir ainda na tentativa de acesso aos materiais presentes tanto no Cedoc e no Museu Casa do Sertão, partindo para uma investigação de cartas de alforria das mães e inventários dos senhores no intuito de investigar mais profundamente a face da história desses seres que tiveram seus direito duplamente negados.

\section{REFERÊNCIAS}

ALANIZ, Anna Gicelle. Ingênuos e libertos: estratégias de sobrevivência familiar em épocas de transição. 1871-1895. Campinas: CMU/Unicamp, 1997

FRAGA FILHO, Walter. Encruzilhadas da Liberdade: histórias e trajetórias de cativos e libertos na Bahia. 1870-1910. Campinas. SP. UNICAMP. 2006.

FRANCISCO, Raquel Pereira. Autonomia e liberdade: os processos de tutela de menores ingênuos e libertos - Juiz de Fora (1870-1900). Especiaria-Caderno de Ciências Humanas. vol.10, n/18, pp649-676, dez. 2007. 
FREIRE, Luiz Cleber Moraes. Nem tanto ao mar, nem tanto à terra: agropecuária, escravidão e riqueza em Feira de Santana, 1850-1888. Feira de Santana. UEFS Editora, 2011.

MATTOSO, Katia de Q. O filho da escrava: em torno da lei do ventre livre. Revista Brasileira de História, São Paulo, v.8, n.16, p.37-55, set. 1988.

MOREIRA, Paulo. Os cativos e os homens de bem: experiências negras no espaço urbano: Porto Alegre 1858-1888. Porto Alegre: EST, 2003.

PAPALI, Maria Aparecida Chaves Ribeiro. Escravos, libertos e orfãos: a construção da liberdade em Taubaté (1871-1895). São Paulo: Annablume, 2003.

PERUSSATTO, Melina Kleinert. Como se de ventre livre nascesse: experiências de cativeiro, parentesco, emancipação e liberdade nos derradeiros anos da escravidão Rio Pardo/RS, c.1860 - c.1888. Dissertação de Mestrado. São Leopoldo, 2010.

SLENES, Robert. Na senzala, uma flor. Rio de Janeiro, Nova Fronteira, 1999.

SOUSA, Ione Celeste Jesus de. Escolas ao Povo: experiências de escolarização de pobres na Bahia - 1870 a 1890. Tese de Doutorado. Programa de Estudos PósGraduados em História/PUCSP: São Paulo, 2006.

SOUSA, Ione C.; MACHADO, M. H. P.T ; CASTILHO, Celso . Porque a ociosidade é a mãe de todos os vicios: tutelas e soldadas de ingênuos na Bahia-1871-1899.. In: Maria Helena Pereira Toledo Machado; Celso Castilho. (Org.). Tornando-se livre: agentes históricos e lutas sociais no processo da Abolição.. $1^{\text {a }}$ ed.São Paulo: UNESPUniversidade de Vanderbilt, 2015.

TEIXEIRA, Heloisa Maria. A não-infância: crianças como mão-de-obra em Mariana (1850-1900). Tese de Doutorado. São Paulo: USP, 2007.

ZERO, Arethuza. O preço da liberdade: caminhos da infância tutelada - Rio Claro (1871-1888). Dissertação de Mestrado. Campinas: UNICAMP, 2004. 